\title{
EDUCACIÓN, UNIVERSIDAD Y LOS PROBLEMAS DE LA CIVILIZACIÓN CONTEMPORÁNEA (2008)
}

\section{Los cursos de Problemas de la Civili-} zación Contemporánea tienen una importancia primordial para la formación que deberían proponerse todas las universidades. Los estudiantes deben sentirse ciudadanos del mundo, conocer sus problemas y comprometerse en la construcción de un mundo mejor.

Además, si conocen estas realidades y sus posibles soluciones, entenderán mejor los problemas de México y encontrarán más fácilmente los caminos más rectos y deseables que deben recorrer.

Estos cursos son apasionantes para todos los hombres que aman al mundo y a todos los hombres del mundo; para los que aman la vida, los encantos de la vida; para todos los que aman la justicia, la paz, la libertad y que por eso odian la guerra, la violencia, la adoración al dinero hasta el desprecio de las personas.

Estos cursos son en verdad apasionantes para todos los que aman la tierra, sus frutos y sus maravillas, y por eso luchan en contra de las agresiones, ofensas y violaciones a la madre tierra.

Son cursos de interés extraordinario para quienes se preocupan mucho más por las personas que por las cosas, para quienes defienden y aprecian la dignidad humana y luchan contra la obsesión patológica y la perversión del Homo oeconomicus que está obscenamente enamorado del dinero, que convierte a las personas en mercancías y en piezas de la gran maquinaria del mercado. 
Estos cursos son necesarios, porque señalan los más escabrosos obstáculos de la educación del hombre humano frente a la formación mercantilista que desata la fabricación en serie impuesta por la oferta y la demanda de los productos humanos de sus funciones y profesiones.

Estos cursos promueven la mismidad, originalidad, autenticidad de las personas frente a la avalancha de los grupos de poder que se proponen convertirlas en dóciles marionetas, finalmente manejadas por otras marionetas.

Aquí se estudian culturas y civilizaciones, estructuras de control y de dominación, que enajenan y corrompen; los grandes riesgos e inmensos retos del hombre contemporáneo incrustado en sistemas de opresión que con frecuencia lo ahogan y le destrozan hasta ese gajo de libertad que constituye el disfrute de la vida y la alegría de vivirla.

Aquí también, la maldición de la guerra y la bendición de la paz, el precio de la liberación, el difícil camino a la libertad, la población creciente y decreciente; los imperios, tronos, dominaciones y potestades; el látigo inmisericorde del mercader que mata de hambre a millones de dignísimas personas por la vileza de un dinero que ensucia las manos y mata a las almas, el cretinismo del poder que coloca a trillones de armas junto a billones de hambrientos; el mundo del absurdo de la droga, del

172 alcohol y del tabaco, del derroche criminal del capital infinito fabricado con el infinito sufrimiento y la sangre de los explotados, de los indigentes, es decir, las diferencias monstruosas de las riquezas que ensucian y de la indigencia mortal.

Sin embargo, estos cursos no se revuelven en un círculo interminable de tragedias, lo que conduciría a la generación de neuróticos anónimos o de innumerables nombres. Conocidos los conflictos en su plena realidad, maestros y alumnos deben realizar un análisis crítico, detallado y formular juicios sobre la naturaleza, complejidad, amplitud y hondura de las causas, relaciones, orígenes de todos los problemas estudiados.

Y después, la tarea más importante: descubrir, construir, imaginar, inventar soluciones; crear utopías de los dos estilos: utopías que denuncian y anuncian (Freyre), pero también las otras de los ideales tan altos que, aunque inalcanzables, ayudan a caminar hacia lo alto. 
Y, por supuesto, de todas estas indispensables tareas debe surgir el compromiso de enrolarse en la lucha obligada para construir un mundo mejor: el mundo del hombre y para el hombre humano.

El pórtico de entrada a estos trascendentales cursos no podría ser otro: la educación y la universidad. La intención es evidente: Solo la buena educación, el crecimiento del hombre humano es la verdadera, tal vez la única solución a los más graves problemas de México y del mundo. Y la auténtica universidad (no ciertamente la mercantilista que pervierte y traiciona su misión) es el medio más adecuado para el desarrollo de ese hombre culto, educado, crítico, con inmensos deseos de superación y transformación que es la única esperanza para construir un mundo mejor.

Es muy acertado y significativo que estos cursos se inicien y terminen con una muy seria reflexión sobre teorías y métodos educativos que tienen como gran objetivo que el estudiante se comprometa con su desarrollo personal, con el de su sociedad y el de su historia (Emmanuel Mounier).

Esencial cualidad de esta educación es el cultivo de la pasión; me refiero al impulso vibrante, a la energía vital, a la voluntad arriesgada, a la determinación inquebrantable. Me refiero a la pasión en la que Hegel pensaba cuando decía: "Nada grande se ha hecho en este mundo sin pasión". La pasión de la que habla Castoriadis cuando afirma que la revolución por la democracia ya no es posible, porque esta requiere pasión por la libertad, por la justicia, pasión por la defensa de la dignidad... Y ahora esa energía se dedica a aprobar las asignaturas del hedonismo en la escuela del permanente placer sin estridencias.

Se necesita la pasión que se propone lo que para el mundo parece imposible, con la fuerza que desborda las medidas del mundo de medidas. Pasión por ideales aún inalcanzables; pasión por la verdad que desprecia las mentiras del mundo de mentiras; pasión por la justicia que no soporta el uso de personas convertidas en ganancias; pasión para condenar la sociedad que aprecia más las cosas muertas que las dolencias vivas; pasión para combatir la demencia del amontonamiento del poder sin rostro que ha impuesto esclavitudes, iniquidades y la aniquilación de los encantos de la vida humana; pasión por las alturas y grandezas 
para despreciar las mediocridades miserables. Sin esta pasión como substancia educativa, a nada de lo grande que requiere el mundo se podrá aspirar.

Eliminada esta pasión del proceso educativo todo terminará en hombres de cabezas uniformes, de pensamientos cortados según pedido para la sociedad de la política de comedia y de caricatura, de la economía que sigue demostrando sus verdades numéricas en el pizarrón de las desigualdades mortales de una sociedad aburrida que consume la belleza de los días en el juego de los gozos y placeres de las ofertas, demandas y utilidades. Sin esta pasión, la educación no vale la pena de ser vivida, no vale la pena ni de ser pensada. Para la educación común, oficial, cuadrada, tibia y chata es mejor aplicar la tesis de Iván Illich: "Hay que desescolarizar la sociedad".

Es por supuesto muy difícil cultivar esa pasión indispensable, pero estos cursos están pensados también para engendrarla. ¿Quién no experimentará rebeldía y coraje al conocer la hechura de las guerras que compran petróleo con vidas humanas? ¿Quién quedará indiferente al contemplar los millones de esqueletos vivientes junto a la destrucción de alimentos para mejorar sus precios o junto al delirante y criminal derroche para la fábrica de la muerte que construye armas y destruye vidas? ¿Quién podrá permanecer insensible ante la destrucción del planeta por satisfacer las exigencias de un mercado regido por la demencia del consumo enajenado que genera el capitalismo salvaje?

Estas y muchísimas otras evidencias ofensivas deben encender el enojo y también la pasión por la lucha para construir un mundo mejor. Otra fuente que puede, que debe promover esta pasión educativa es lo que yo llamaría el proceso de simbiosis. No ya el cauce de las razones, sino la vertiente de la vida. Me refiero a la actitud del maestro. Si el maestro considera con fría racionalidad los problemas, sin duda comunicará frialdad e indiferencia. Si por el contrario siente pasión en la condena y en la denuncia de tantas inequidades, de tantas injusticias criminales, entonces contagiará su pasión por la verdad, por la justicia, por la libertad, por la humanidad entera; contagiará esa pasión indispensable, necesaria para el compromiso. 
Otra dimensión educativa esencial y urgente es la actitud de respuesta justa a la sociedad. Narro un caso real de un contenido pedagógico admirable: una madre fue abandonada con ocho hijos pequeños. Lavaba y planchaba ropa para mantenerlos. Los niños asistían irregularmente a la escuela, porque también ayudaban con la venta de chicles a la economía familiar. El maestro de primaria comprobó que el tercero de los niños tenía un muy alto coeficiente intelectual e insistió a la mamá en que lo ayudaran para que pudiera dedicarse al estudio. La señora se resistía, pero finalmente decidió aumentar sus horas de trabajo y dar algunas cajas más de chicles para que los otros hermanos los vendieran.

El hijo consentido fue un estudiante notable. En la universidad, antes de terminar su carrera, ya suplía a sus profesores y daba algunas conferencias.

El día de la recepción del hijo privilegiado, la mamá, los hermanos y todos los habitantes de la vecindad estaban felices preparando la fiesta para el que ya era orgullo de toda la familia. Era esperado con ansias entre cadenas de papeles de colores y cantos de júbilo desde las seis de la tarde. Pasaron las siete, las ocho y las nueve. Finalmente, el hermano mayor fue en busca del graduado. Lo encontró en un lujoso antro celebrando con maestros y compañeros, entre brindis de tequilas y mariachis. Se acercó a él y le dijo después de felicitarlo: "Hermano mío, nuestra madre, hermanos y vecinos te hemos estado esperando desde hace tres horas para abrazarte y felicitarte. Tú sabes bien que eres nuestro orgullo y nuestra esperanza, ¿cómo es posible...?” El ya licenciado interrumpió y, con voz dura le dijo: "Mamá, ustedes y todos los vecinos deben comprender que yo ya pertenezco a otra clase social. ¡Olvídenme como yo los he olvidado!" Y siguieron los brindis y los mariachis...

Es imposible encontrar un adjetivo apropiado para calificar a ese adefesio humano. Llamarlo "bestia" sería muy impropio e injusto. Ningún animal se comporta así en el reino de las bestias. ¡Pagar de esa manera los heroicos sacrificios de la madre y de los hermanos, el respaldo de los vecinos que hacían rifas para comprar los libros caros, va más allá de la imbecilidad y del cretinismo! En la vecindad todos se quedaron esperando. El graduado, instalado en su "nueva clase social" nunca volvió a ver a su familia, que lo avergonzaba. 
Pues bien, la parte siguiente es la más perversa y devastadora; porque el caso narrado es de un solo individuo. La verdad más cruel es que la gran mayoría de los egresados de las universidades e institutos de educación superior tienen un comportamiento muy semejante. Casi todos los estudiantes (aun los de instituciones privadas) son sustentados con un gasto social que se sustrae de los más necesitados (alimentación, educación, salud, vivienda digna). Se suele argumentar que la mejor inversión distributiva es la que se destina a la educación superior, porque después los egresados, formados, profesionistas ayudarán a que los marginados mejoren su situación.

Pero ¿qué sucede en realidad? La enorme mayoría de los privilegiados celebran su graduación en lujosos antros, explotan el valor de sus títulos para su propio beneficio y nunca vuelven a la vecindad social, porque ya pertenecen a "otra clase".

Este es, sin duda alguna, uno de los más graves pecados sociales que no pueden tener perdón en el reino de la justicia.

Muchas universidades intentan escapar a la culpa y la condena afirmando con energía que la universidad cumple su compromiso de justicia con la sociedad si "produce" profesionistas muy capaces (economistas, ingenieros, abogados...). El argumento es gravemente falso, porque conocemos demasiados brillantes egresados de brillantes universidades de primer mundo que usan sus exquisitas ciencias y técnicas para hacer sus dictaduras más eficaces, sus conquistas más feroces, sus métodos de explotación más productivos; para hacer su capitalismo más salvaje.

No es necesario, pero sí muy conveniente, repetir que el deber de responder a la sociedad, de retribuirle por lo menos en la medida de lo que de ella se ha recibido es una cuestión de justicia, de estricta justicia conmutativa. No es ciertamente un asunto de caridad.

Basta con unas cuantas lecturas de esta materia de Problemas para percibir con entera claridad que el sistema político y socioeconómico que predomina en el mundo está en quiebra: En el plano social, la quiebra es evidente por la enajenación, la cosificación, la idiotización del hombre contemporáneo (Erick Fromm, Jean Baudrillard, Robert Linhart, Ray D. Bradbury, Aldoux Huxley). 
En el plano político, nunca ha sido más diáfana la mentira del “gobierno del pueblo y para el pueblo", y la gran verdad de la política como el arte de conquistar y conservar el poder por todos los medios: guerras, crimen organizado, órganos ocultos, élites perversas (Norberto Bobbio, Ignacio Ramonet, Manuel Castells, Herbert Radtke, Susan Sontag).

Y en el plano económico, la quiebra no puede ser más contundente, si se sigue aceptando que la economía es la ciencia que tiende a hacer posible lo necesario y que el desarrollo económico se sustenta sobre el crecimiento y la distribución equitativa. Nunca como ahora las desigualdades han sido más ofensivas y mortales (ricos, pobres y ultrapobres, Carlos Berzosa, el desorden neoliberal; Pedro Montes, el malestar de la globalización; Joseph Stiglitz). Nunca como ahora las corporaciones internacionales han tenido tanto poder, control y dominación (The Corporation); nunca como ahora había habido tan escandaloso número de muertos por hambre al año (40 millones, según el PNUD), y al mismo tiempo, nunca habían alcanzado cifras billonarias tan escandalosas los hombres más ricos del mundo.

Todos estos datos ofensivos y criminales adquieren una dimensión inalcanzable si se recuerda la afirmación de André Gorz: "Basta que un niño llore de hambre en cualquier choza del mundo, para cuestionar todos los sistemas sociales, políticos y económicos".

Y ¿qué decir del alto crecimiento demográfico de los países pobres? La ONU y los organismos internacionales financieros dicen que el aumento de la población es la causa del subdesarrollo y llegaron, apoyados por el entonces presidente Clinton, a promover la cínica medida de la legalización del aborto como medio de control natal. La iniciativa es infame y tendía a la justificación del abuso de los poderosos sobre los débiles, puesto que el gran Josué de Castro ya había demostrado que la relación es a la inversa: el subdesarrollo es la verdadera causa del alto crecimiento demográfico.

Así pues, si en verdad quisieran resolver el problema, los poderosos países del "primer mundo" deberían, ante todo, dejar de explotar a los países del tercero y quinto mundos, y además, ayudarlos a su desarrollo. 
Como se advierte, todos problemas sociales están íntimamente relacionados y siempre se encuentra de forma mediata o inmediata la causa, por la que Iñaki Ellacuría calificaba a este sistema de abusos como intrínsecamente perverso: poner el dinero por encima de las personas y usar a las personas como medios de producción de dinero (otra vez: Homo oeconomicus vs. Homo sapiens).

Y si quedara alguna duda sobre esta relación y causa abrumadoras, allí tenemos el inmenso bloque de tragedias que se viven en el hábitat. Seguramente el problema más imponente y terrible que vivimos es el sistema perfectamente coordinado de agresión al planeta.

Afortunadamente, ya hay una aceptación unánime de que se está dando un proceso destructivo del maravillosísimo sistema de equilibrio ecológico. Lo más notorio es el calentamiento de la atmósfera y todo lo que lleva de causas y efectos; pero junto a este fenómeno hay infinitas acciones, consecuencias y reacciones que manifiestan el dolor inmenso de la madre tierra.

En el momento actual resulta no solo inaceptable, sino también ridículo y hasta delictivo que las máximas autoridades de los Estados Unidos sigan negando las evidencias de las causas y hechos de la destrucción ecológica y se sigan oponiendo a los compromisos de Río (Bush padre)

178 y de Kioto y Bali (Bush hijo).

Por otra parte, es muy comprensible que estas "personalidades" prefieran defender los votos para sus elecciones que el bienestar de la tierra, siendo, como son, los máximos representantes del capitalismo apellidado "salvaje", el que no puede subsistir sin el consumismo y el uso compulsivo de los recursos no renovables. ¡Qué difícil hacer comprender al hombre contemporáneo la lección del indio Seattle: la tierra no pertenece al hombre! ¡El hombre pertenece a la tierra! O al menos, que piense en serio si "tienen derecho las rocas" (Nash Roderick).

Si todas estas agresiones a las personas y a la naturaleza no son pruebas suficientes para hablar de la quiebra del sistema global, entonces será necesario cuestionar el valor de significantes y significados.

Sería más que insensato en el plano educativo que, si el mundo está en quiebra, se siga privilegiando la memoria para repetir las mismas materias, las mismas teorías económicas, políticas y sociales que han 
producido esta situación de injusticia y de vergüenza. Es necesario decirlo: mantener teorías y estructuras de este sistema que favorece a muy pocos, a costa del sacrificio y muerte de la mayoría, significa ser cómplices de tal perversión.

El reto ineludible para evitar tan inmoral complicidad es inventar, crear opciones en todos los ámbitos del quehacer humano. La invención debe ser la actividad más cultivada y mejor remunerada, dice Jacques Attali, autor de El milenio.

La memoria, facultad más premiada en nuestros procesos educativos, debe ser suplantada por la inteligencia y por la imaginación. El alumno que mejor repite y, por eso, el más apreciado en los criterios escolares vigentes debe ser sustituido por el que mejor piensa, imagina e inventa. Lo mismo es posible decir de las instituciones educativas: en vez de construirse sobre la repetición de las mismas carreras con los mismos programas y materias, se podría pensar en grandes espacios dedicados a la reflexión y al descubrimiento.

Un extraordinario ejemplo de que esto es posible es la Universidad de Manhattan, subsidiada en su inicio por David Rockefeller y dedicada expresamente a la investigación, a la invención, a la imaginación sin límites. ¡Cualquiera diría que es un desperdicio de recursos! Sin embargo, de esta "pequeña universidad" ya han salido varios premios Nobel y reconocimientos de carácter internacional.

En el ámbito empresarial se ha pensado que la única esperanza defendible y costeable es aquella que se propone y logra las mayores ganancias. No importa que las personas sean usadas como mercancías, como medios de producción, que sean pagadas a un precio mínimo, porque en la oferta de mano de obra, el ejército de desempleados es enorme.

Un joven sacerdote vasco puso en duda los dogmas capitalistas empresariales. Con imaginación y gran respeto a la dignidad de las personas, con pocos trabajadores desempleados, inició una nueva forma de trabajar con normas y criterios radicalmente diferentes: "aquí lo más importante es la persona" (lema central). Dinero y capital son instrumentos. Todos los trabajadores son propietarios. La asamblea general es la máxima autoridad (auténtica democracia). Pequeña dife- 
rencia salarial. Trabajo de acuerdo con aptitudes e intereses (trabajo personalizante).

Los empresarios capitalistas dijeron: el destino de esta cooperativa de Mondragón es un seguro fracaso. En el momento, actual es una de las multinacionales más prósperas. Esta es una excelente demostración de que una empresa que pone a las personas por encima del dinero no solo puede tener éxito económico, sino que este es más seguro y estable. En otros términos, se demuestra que sí es posible armonizar los principios éticos (el hombre considerado como fin, no como medio, bien común, solidaridad y subsidiaridad) y la eficiencia empresarial.

Otro notable ejemplo de las grandes cosas que se pueden hacer con imaginación y determinación para lograr un mundo mejor y diferente es el caso de Mike Cooley, un brillante ingeniero que trabajó muchos años en la British Lucas Aerospace, una de las trasnacionales productoras de armas más poderosas de Occidente. En 1980 decidió ya no emplear su talento en armas destructivas, sino en el diseño de tecnologías alternativas. Él y un grupo de obreros que lo siguieron llegaron a producir hasta 150 inventos socialmente útiles, entre ellos un carrito maravilloso para niños con espina bífida, que le merecieron el premio Nobel de alternativas. Llegó a ser director de la fundación London Technology Network, que coordina trabajos de universidades y tecnológicos orientados al desarrollo de productos y sistemas ecológicos.

Inmensa satisfacción ha experimentado Mike Cooley por haber dejado la fabricación de instrumentos para la muerte y por haber dedicado sus capacidades y talentos al servicio de la calidad de vida, especialmente de los niños, y a la conservación del planeta.

Estos ejemplos (tomados todos de la materia de Problemas de la Civilización Contemporánea) manifiestan que por el camino de la imaginación y de la creatividad puede pensarse y construirse un mundo mejor. También resulta evidente que hay soluciones a los grandes conflictos existentes: es la parte esencial del curso.

Eso expresan también y con un énfasis impresionante Susan George en Otro mundo es posible: el movimiento de los ciudadanos del mundo y Manuel Castells en Entender nuestro mundo (donde afirma que nada hay tan grave que no pueda cambiarse si se emplean los medios adecuados) 
o el muy distinguido premio Nobel de Economía Joseph Stiglitz, que hace una fuerte crítica al sistema que pretende eliminar cualquier intervención del Estado para entregar la máxima libertad al mercado. Muy valioso en este sentido es el contenido de las encíclicas Centesimus Annus y Populorum Progressio, que señalan soluciones y respuestas en las dimensiones del mundo material, pero también desde la inspiración del espíritu y de la fe. La gran dificultad, sin embargo, no radica en mostrar y demostrar los caminos de solución, cambio y transformación, sino en encontrar a quienes decidan caminarlos.

Aquí de nuevo se pone de manifiesto la inmensa importancia de la educación y de la universidad, y al mismo tiempo se evidencia la gravedad del problema que significa la pobreza (a veces miseria) de muchas universidades y, en consecuencia, la pobreza (a veces miseria) de la educación que imparten.

La gran mayoría de las instituciones universitarias han cedido a la tentación del dinero y se han convertido en empresas mercantiles regidas por las leyes del mercado. Con mucha razón los dignos representantes del movimiento de 1968 gritábamos: Estamos hartos de ser tratados como mercancías, exigimos ser tratados como personas. (Parecería que después de 40 años de aquel grito de dignidad universitaria casi todas las instituciones de educación superior han vuelto a usar o han seguido usando el perverso sistema que emplea a profesores y a estudiantes como medios de producción de ganancias. Ahora su competencia se ha centrado en el modo de generar las mercancías más costeables para los mercados oficiales, públicos o privados.)

Es, en verdad, ignominioso que tantas instituciones que están llamadas a combatir la corrupción y a generar esperanza terminen siendo corruptas y engendren desesperanza. Instituciones que por su naturaleza deberían resolver los problemas, se convierten en graves problemas (es pasmoso el dato de la ANUIES de que más del 93\% de las universidades se dedican al fraude y a la mediocridad).

Los más graves problemas de México y del mundo solo pueden ser resueltos por personas de gran calidad humana, con un alto desarrollo del pensamiento crítico, con imaginación y creatividad, con alto sentido de responsabilidad social y con la vivencia de valores inherentes 
a la dignidad como la justicia, la libertad, la honestidad, la integridad (cualidades que se propone nuestra educación universitaria). Es obvio que la institución más indicada para favorecer la generación de estos hombres es la universidad. Por eso he dicho que cuando no cumple su gran misión, se convierte ella misma en un grave problema, porque escuelas mediocres y mercantilistas no solo no pueden favorecer el crecimiento de las personas, sino que destruyen la gran fuente de riqueza humana y, más bien producen profesionales con criterios utilitaristas, pragmáticos y también mercantilistas y mediocres.

En el curso de Problemas de la Civilización Contemporánea se debe poner un énfasis especialísimo en el plano de las soluciones, sobre la insustituible necesidad de buenas, de auténticas universidades, ya que estas son la inteligencia de los pueblos, la conciencia crítica de la sociedad, el cerebro del cuerpo social.

Por eso, hay que decirlo con insistencia: la universidad debe ser "el recinto sagrado de la razón" (Jaspers), la casa en que maestros y alumnos se reúnen para pensar (Newman), la comunidad que piensa los problemas del mundo y a nosotros en el mundo (Hutchins), casa construida para pensar.

La relación intrínseca entre el quehacer esencial de la universidad y la solución de los más graves problemas de México y del mundo está brillantemente expresada en una pintura de colores tormentosos en la que aparece el Homo sapiens enjuto, abofeteado, lanzado sobre la lona por el enorme Homo oeconomicus, obeso y obsceno. Es una pintura de la verdad del mundo contemporáneo. De allí la importancia de pensar, de pensar lo grande. La única opción para todos los que apostamos por el Homo sapiens como regente del mundo es alimentarlo, fortalecerlo con el pensamiento, la reflexión, el análisis crítico para ganar las batallas al imperialismo internacional del dinero.

En nuestro mundo, en el que lo único seguro es la inseguridad, en el que no podemos prever ni siquiera lo que va a suceder mañana, lo único verdaderamente sensato es, como dice Paul Valery, estar preparado para afrontar (con la sabiduría del Homo sapiens) con lucidez intelectual y calidad humana lo que venga. 
Por otra parte, debemos esperar y en lo posible exigir que la universidad, en estos momentos de tantas oscuridades, no abandone, no traicione su misión de ser luz, de proyectar luz y de ser el limpio abrevadero del Homo sapiens.

Debemos esperar y, en lo posible, exigir que las universidades traten a los estudiantes de acuerdo con su dignidad, de acuerdo con sus derechos de ser considerados como personas con cualidades y potencialidades inmensas, aunque inmensurables. ¡Qué comprendan estas instituciones que no deben ser ni forjadoras, ni maquiladoras de personalidades, ni apéndices de los poderes políticos o económicos ni tampoco ser conservadoras o promotoras de las ideologías dominantes!

Debemos exigir, los que no aceptamos la degradación mercantilista de la universidad, que esta dignísima institución cumpla su trascendental obligación de servicio: ofrecer los medios necesarios para propiciar el desarrollo moral, estético, intelectual y espiritual de todos sus integrantes y que se concentre en descubrir los medios más convenientes para que el estudiante aprenda a pensar lo grande (Newman), que pueda generar ideas propias, vida propia, cultivando el parto de las almas (Vasconcelos), que llegue a experimentar el gozo de la verdad (Gadamer), que sepa iluminar los caminos que conducen de las sombras de la caverna a la luz de la verdad (Platón), que proporcione elementos intelectuales y prácticas de auténtico servicio social para que los estudiantes y maestros se comprometan con su desarrollo personal, pero también con una sociedad mucho más libre, más justa y más humana.

Después de estas reflexiones creo que es legítimo reafirmar la inmensa importancia de conocer los problemas de la civilización contemporánea, de analizarlos críticamente, de descubrir, inventar, encontrar soluciones y comprometerse en serio con la construcción de un mundo mejor. Creo también que es evidente la necesaria aportación de la buena, de la auténtica universidad que favorezca la buena, la auténtica educación, sin la cual ningún cambio substancial, deseable, será posible. 
CITAM Derechos Reservados.

La reproducción total o parcial de este artículo se podrá hacer si el ITAM otorga la autorización previamente por escrito. 